\title{
EDUCAÇÃO E HUMANIZAÇÃO: POÉTICA DA CONDIÇÃO HỦMANA
}

\author{
Ailton Siqueira de Sousa Fonseca ${ }^{1}$ \\ Charles Lamartine de Sousa Freitas ${ }^{2}$ \\ Rosilene da Costa Bezerra Ramos ${ }^{3}$
}

\begin{abstract}
RESUMO
A reflexão proposta neste ensaio coloca em tela a Educação como lugar investigativo privilegiado para se pensar a formação humana. Educação aqui defendida não como um projeto que limita o seu propósito ao viés mercadológico, em detrimento do mote principal do processo formativo, a saber, a humanização dos sujeitos. Trata-se deeducar para os novos desafios do homem contemporâneo, que precisa primeiramente se conhecer e saber conviver em meio à diversidade para, então, compreender a ontologia da condição humana. Refletir sobre o caráter humanizador da educação é imprescindível à compreensão das adversidades que envolvem os processos educativos atuais, umavez que reivindica um projeto em que o sujeito desvele e resgate a sua identidade humana. Um modelo urdido por princípios éticos, estéticose humanitários, potencializadores da dimensão do existir e parte da totalidade do que é ser pessoa. O texto a seguir busca proporcionar reflexões sobre outras formas do viver a educação. É possível mirar nossa lente para a necessidade do educar, ancorada à sensibilidade dos gestos poéticos na formação humana, tarefa urgente em um tempode desesperança.
\end{abstract}

Palavras-chave: Humanização; Condição Humana; Educação dos Gestos Poéticos.

\section{EDUCATION AND HUMANIZATION: POETICS OF THE HUMAN CONDITION}

\footnotetext{
1 Doutor em Ciências Sociais pela PUC/SP. Professor do Departamento de Ciências Sociais e Política da UERN. Professor do Mestrado Interdisciplinar em Ciências Sociais e Humanas da UERN e coordenador do Grupo de Pesquisa do Pensamento Complexo (GECOM/UERN). E-mail: ailtonssfonseca@gmail.com.

2 Graduado em Serviço Social e Teologia. Mestre em Teologia pela Pontifícia Universidade Gregoriana(Roma/ltália). Mestre em Educação pela Universidade do Estado do Rio Grande do Norte (UERN). Doutorando em Educação pela Universidade Estadual de Campinas (UNICAMP), na área de Filosofiae História da Educação. É Diretor Geral da Faculdade Católica do Rio Grande do Norte (FCRN). E-mail:charles.lamartine@gmail.com.

3 Graduada em Pedagogia pela Universidade do estado do Rio Grande do Norte (UERN). Especialista em Educação pela Universidade do Estado do Rio Grande do Norte (UERN) e em Atendimento Educacional Especializado na Perspectiva pela Educação Inclusiva pela Universidade Estadual Paulista Júlio de Mesquita (UNESP). Mestra do Programa de Pós-graduação em Educação (POSEDUC/UERN). Membrodo Grupo de Estudos e Pesquisas em Memória, (Auto) Biografia e Inclusão (GEPEMABI) Faculdade deEducação/UERN. E- mail: rosilenerb@hotmail.com.
}

Rev. Omni. Sap., Mossoró, v.1, n.1, p. 13-25, ago./nov. 2021.

DOI: 10.29327/240437.1.1-1 


\begin{abstract}
The reflection proposed in this essay places Education as a privileged investigative place to think about human formation. Education here defended not as a project that limits its purpose to the marketing bias, to the detriment of the main motto of the formative process, namely, the humanization of the subjects. It is about educating for the new challenges of contemporary man, who first needs to know himself and know how to live in the midst of diversity in order to then understand the ontology of the human condition. Reflecting on the humanizing character of education is essential to understanding the adversities that surround the current educational processes, since it demands a project in which the subject unveils and rescues his human identity. A model woven by ethical, aesthetic and humanitarian principles, enhancing the dimen-sion of existing and part of the totality of what it is to be a person. The following text seeks to provide reflections on other ways of living education. It is possible to aim ourlens at the need to educate, anchored to the sensitivity of poetic gestures in human formation, an urgent task in a time of hopelessness.
\end{abstract}

Keywords: Humanization; Human Condition; Education of Poetic Gestures.

\title{
1 INTRODUÇÃO
}

As reflexões aqui apresentadas emergiram das discussões e estudos forjados na elaboração do componente curricular Educação e humanização: poética da condição humana para os cursos da Faculdade Católica do Rio Grande do Norte (FCRN). Considerando a realidade em que vivemos e os desafios de ser e viver-juntos desafios esses que se acentuam cada vez mais diante da nossa realidade marcada pelo individualismo, por concorrências, guerras, inseguranças, insensibilidades e medos - compreendemos que a educação não deve deixar de ensinar o conhecer e o fazer, mas é fundamental e urgente se preocupar com a condição humana e com a formação humanista dos sujeitos de nosso tempo. Essa formação deve ir além das exigências técnicas, profissionais e especializadas para o mercado de trabalho. Essa educação será, pertinentemente, alicerçada em outros valores e princípios humanizantes como resposta a esse crescente trabalho maquínico na sociedade, à banalização das relações e dos afetos humanos que, pouco a pouco, torna o ser humano cada vez mais desumanizado e a vida sem significado. Em uma palavra: a educação se coloca diante do novo desafio de (re)construir uma outra imagem de ser humano, de enxergar a verdadeira natureza ou a essência do "humano do humano" que está em nós, e é isso que faz de cada indivíduo e de toda a humanidade, ao mesmo tempo, universal e singular. Empregada pelo filósofo Jean-Paul Sartre (1986), pela escritora Clarice Lispector (2007) e tantas vezes por Edgar Morin (2000, 2002), a expressão "humano do humano" nos faz (re)pensar sobre o que faz de nós o que nós somos, pois, como bem esclarece Morin:

Todo ser humano, mesmo aquele fechado na mais banal das vidas, constitui ele próprio um cosmo. Traz em si multiplicidades interiores, personalidades virtuais, uma infinidade de personagens quiméricos, uma poliexistência no real e no imaginário, no sono e na vigília, na obediência e na transgressão, no ostensivo e no secreto (...). Cada qual contêm em si galáxias de sonhos e de fantasias, impulsos de desejos e amores insatisfeitos, abismos de desgraças (...), acessos de ódios, desregramentos, lampejos de lucidez, tormentas dementes (MORIN, 2000b, p. 57).

Para Morin, cabe à educação mostrar, ilustrar, compreender e ensinar a complexidade da condição humana ao próprio sujeito. Precisamos, assim, de uma abordagem aberta 
à existência, à angustia, ao gozo, à dor, ao êxtase Morin (2020, p. 17), abordagem que vá além do aprender a conhecer e do aprender a fazer, mas que invista esforços práticos e cognitivos nos aspectos sensíveis, subjetivos e póeticos da existência humana. Isso se torna pertinente e urgente posto que "a confusão existente no mundo surgiu porque o indivíduo não foi educado para compreender a si próprio" Krishnamurti (s.d. p. 28), e nem aos outros. Movido pela lógica mercadológica de produção e consumo, o sujeito anda, infelizmente, tão ocupado com as coisas da mente e do trabalho, que pouco tempo Ihe resta para atender às demandas do coração. Trata-se, assim, de considerar uma formação integral da condição humana em suas diversas relações consigo mesmo e com os outros.

Nessa perspectiva, um dos primeiros e mais constantes questionamentos que a educação deve levantar é sobre o significado da vida pessoal e coletiva. Se pensássemos sobre a vida, talvez houvesse menos violência no mundo e mais solidariedade nas relações, talvez existisse mais amor, amizade, alegria e segurança, isto porque não veríamos o outro como um concorrente, um inimigo e vice-versa. Pensamos, em consonância com Krishnamurti ([s.d.], p. 85), que somente quando começarmos a compreender o profundo significado da vida humana é que haverá a verdadeira educação. Falta-nos, sem dúvidas, uma educação e um ensino para a sensibilidade, para a vida, para a humanização do próprio ser humano, tendo em vista que este é cada vez mais consumido por tudo o que ele mesmo consome.

Há muito tempo Gandhi já defendia uma educação do coração, algo que despertasse a alma do ser humano que, por sua vez, está sendo consumida, pouco a pouco, pelo mundo do trabalho e tornando-se alienada num universo que ela mesma pretende compreender. Muito tempo antes de Gandhi, Jean-Jacques Rousseau (2004, p. 5), já propunha uma educação conveniente ao homem e bem adaptada ao coração humano. Rousseau foi um dos primeiros pensadores a defender uma educação voltada para a formação humana e para o aprender a ser. Para ele:

O objetivo que devemos nos propor na educação de um jovem é o de formar-lhe o coração, o juízo e o espírito. A maioria dos mestres, sobretudo os pedantes, veem

a aquisição e empilhamento das ciências como único objeto de uma bela educação, sem pensar que frequentemente, como diz Molière, 'um tolo sábio é tolo mais do queum tolo ignorante’ (ROUSSEAU, 1994, p. 45).

Sem investir nessa compreensão, a educação e a cultura vão construir, cada vez mais, um ser humano ligado ao mundo, mas apartado de si próprio, um sujeito dominador de técnicas e hábil profissionalmente, mas inábil a perceber o lado sensível da concretude do mundo e da vida. Quando o ensino não coloca os aspectos da vida e do ser humano em primeiro lugar, o saber só pode levar a sofrimentos, alienações, cegueiras cognitivas, apartações de todos os tipos, a confusão e a desorientação.

Percebemos, contudo, que ainda há na sociedade e na educação uma hiper valorização da racionalidade, da técnica, da objetividade e uma desvalorização das emoções e sensibilidades humanas enquanto construtoras de saberes e experiências importantes sobre nós mesmos e com-os-outros. Esse componente curricular, Educação e humanização: poética da condição humana, intenciona superar as dicotomias do pensamento e as limitações relacionadas àquilo que Edgar Morin chama de "humano do humano". Ele se apresenta com o intuito de contribuir fortemente para a sensibilização 
da razão, para o despertar dos sentidos humanos que fundamentam a discussão cerne deste trabalho/propósito. Além disso, convidando-nos a refletir sobre a Educação como lugar investigativo privilegiado para se (re)pensar a formação humana em sua integralidade. Um solo fértil onde possamos cultivar a nossa própria humanidade. Um debruçar na busca de um conhecimento mais pertinente sobre a frágil e complexa condição humana. Compreender os paradoxos e ambiguidades do "humano do humano" nos ajudará a nos entender, a entender os outros e sermos entendidos. Concebemos, como Sartre, que esse "compreender é a um só tempo uma relação prática e uma relação humana de amizade, de amor; amar, compreender, agir-em-conjunto é uma única e mesma coisa" (SARTRE, 1986, p. 89). Assim, esse componente curricular se coloca no desafio de contribuir para novos laços societários tecidos pela solidariedade, pelo amor, respeito, compreensão e para a cultura da paz.

\section{EDUCAÇÃO E HUMANIZAÇÃO: A EDUCAÇÃO COMO MEIO DE HUMANIZAR O SER HUMANO}

Se revisitarmos a história da humanidade, conseguiremos perceber que o homem nasce em sua espécie, porém necessita humanizar-se. Mas o que nos torna humano? Sem a cultura, sem linguagem, o homem não se humaniza. Ao adquirirmos essa cultura, materializamos o conjunto de características das qualidades humanas. Diante dessa premissa, a educação passa a assumir um lugar privilegiado na sociedade, sendo essencial ao processo de humanização por possibilitar o encontro com o outro por meio de experiências formativas e transformativas do sujeito. Os processos socioculturais e educacionais nos fazem superar a condição de homem biológico e nos torna homem cultural e social. Saviani (1991, p. 21), argumenta que:

\footnotetext{
[...] o trabalho educativo é o ato de produzir, direta e intencionalmente, em cada indivíduosingular, a humanidade que é produzida histórica e coletivamente pelo conjunto doshomens. Assim, o objeto da educação diz respeito, de um lado, à identificação dos elementos culturais que precisam ser assimilados pelos indivíduos da espécie humana para que eles se tornem humanos e, de outro lado e concomitantemente, à descoberta das formas mais adequadas para atingir esse objetivo.
}

Ao pensar o ser humano histórico e socialmente construído e, portanto, com possibilidades de mudanças, é preciso lançá-lo diante de um movimento reflexivo que o leve a superar sua consciência ingênua do mundo e questionar criticamente os fatores condicionantes, inferindo, dessa forma, a concepção de ser humano, algo que só pode acontecer na relação com o outro, posto que ninguém se faz sozinho. Ser significa ser com-o-outro. Nessa perspectiva, o sujeito percebe o que é e o que pode ser. A descoberta do outro passa, necessariamente, pela descoberta de si e vice-versa. Como argumenta Jacques Dolors (2001, p. 98), a educação deve ajudar os sujeitos/ alunos a descobrirem a si mesmos. Só então poderão pôr-se no lugar dos outros e as suas reações. É nesses processos que o sujeito se percebe como um ser que estarsendo, fazendo-se em tudo que ele mesmo faz. Então, compreender a si próprio ocorre no exercício de compreender o outro: compreender-se compreendendo.

É sabido que educar é, essencialmente, uma ação humana. Somente o homem pode formar outro homem. Educamo-nos na relação com os outros seres humanos. $O$ processo de constituição do sujeito é essencialmente relacional. Encharcados em nossas 
relações, aprendemos a ser gente. Segundo Freire (1983), educar é "construir gente", humanizar o sujeito na luta em denunciar e superar os elementos desumanizadores.

Aprender a ser e aprender a viver-junto, com-o-outro Dolors (2001), é uma necessidade urgente para uma vida em comum, coletiva e em paz. Sem isso, iremos nos destruir porque o homem perde sua humanidade. Neste sentido, o objetivo primeiro da educação é ensinar isto, porque desaprendemos o valor daquilo que vale a pena viver, o valor que tem a vida humana e, assim, combateremos a banalização do mal generalizado. Educar é, portanto, uma ação humana e humanizadora.

Daí compreendemos que a educação, além de um direito de todos, é condição fundamental para a humanização. Como argumenta (NUNES, 2019, p. 36):

[...] A compreensão da Educação como processo de humanização, isto é, de constituição do caráter propriamente humano de nossa identidade ontológica, nos desafia a pensar a necessidade de inserir a plataforma de conteúdos e de práticas que se reconhecem como Direitos Humanos no seio desse projeto e desse processo social e cultural.

Essa proposição corrobora com o nosso posicionamento em chamar atenção para a importância do papel da educação enquanto promotora do desenvolvimento e da formação humana dos indivíduos e das sociedades. Essa educação, ou como diz Dolors (2001, p. 96), esta aprendizagem, representa hoje um dos maiores desafios à educação, tendo em vista que a história humana sempre foi conflituosa, apesar de percebermos que há elementos novos que acentuam o perigo e, especialmente, o extraordinário potencial de autodestruição criado pela humanidade no decorrer do século XX. A Educação, sendo um tesouro a descobrir, não pode deixar de explorar nenhum dos talentos que constituem a interioridade de cada ser humano: memória, raciocínio, imaginação, capacidades físicas, sentidos estéticos, facilidade de comunicação com os outros e o carisma natural para animador. O que só vem confirmar a necessidade de cada um se conhecer e se compreender melhor (DOLORS, 2001, p. 20).

Sabemos que a vida pulsa para além da transmissão dos conhecimentos instituídos. Escutar, olhar, ver, sentir e tocar os significados e percepções do outro não apenas pela memória como também pela voz que anuncia, propicia-nos sentir com esse outro todas as subjetividades possíveis, assim como as emoções essenciais à construção do ser: alegria, tristeza, angústia, sofrimento e paixão.

É importante ressaltar que um componente curricular como esse, que se propõe investir esforços práticos e cognitivos na utopia possível de humanização do homem, não deve ser somente consciente da realidade na qual se insere, mas ter olhos voltados para si mesmo. Humanização não se ensina. Aprende-se juntos. A necessária crítica deve, pois, ser acompanhada constantemente pela autocrítica, a análise pela autoanálise, 0 olhar para o outro como uma extensão do olhar sobre si mesmo. Isso se torna relevante porque a desumanização que desejamos combater no outro e no mundo também está em nós, a humanização que pretendemos (re)construir por meio das práticas educacionais começa em nossa própria sala de aula e em nossa própria vida de educadores. Em uma palavra: aquilo que quereremos fazer para o outro é um exercício que fazemos com ele: fazemo-nos naquilo que fazemos, juntos, implicados. Não podemos chegar ao outro sem passar por nós mesmos. Ou, nas palavras do psicanalista Eugène Enriquez (1994), o caminho para o outro é também caminho para si. Nesse processo, aprendemos que é impossível obrigar alguém a sentir, mas o que nós sentimos pode contagiar os outros. A prática educacional humanizadora deve ser algo contagiante. Mais do que tocar, trata-se de despertar, estimular, fazer acreditar em utopias possíveis Rev. Omni. Sap., Mossoró, v.1, n.1, p. 13-25, ago./nov. 2021. 
e em sonhos realizáveis.

Na trilha do pensar a educação enquanto meio para a humanização, as palavras do crítico literário Candido (1989, p. 117) ecoam em nosso ensaio. Segundo ele, a humanização é:

[...] o processo que confirma no homem aqueles traços que reputamos essenciais, como o exercício da reflexão, a aquisição do saber, a boa disposição para com o próximo, o afinamento das emoções, a capacidade de penetrar nos problemas da vida, o senso da beleza, a percepção da complexidade do mundo e dos seres, o cultivo do humor.

Nessa perspectiva, defendemos que é por meio do elo propiciado pela educação que a humanização se processa. Humanização aqui é entendida como o processo de sensibilizar os sujeitos, de apropriação dos conhecimentos e características humanas construídas socialmente e disseminadas por meio da cultura. Humanizar é educar para os novos desafios do homem contemporâneo, perante o mundo, a si mesmo e o outro que precisa se conhecer e conviver em meio à diversidade, ao internalizar profundos sentimentos de solidariedade para o reconhecimento da dignidade da pessoa humana. O grande desafio de uma educação humanizadora é o fazer-se humano em um processo dialético, onde o homem contribui para o capital cultural humano na medida em que forma sua subjetividade. Como dissemos anteriormente, significa dizer que o homem se faz em tudo aquilo que ele mesmo faz. Faz-se com os outros naquilo que fazem juntos. Esse modelo educacional se torna, assim, pertinente e urgente para uma formação humana à altura do que se exige a realidade e os desafios cotidianos.

Para enfrentarmos a desumanização crescente do mundo, a fragmentação dos saberes e das práticas educativas, faz-se necessário, constantemente, repensarmos nossos pensamentos, revermos nossas visões, percebermos o lado sensível da concretude do mundo, estimularmos a razão sensível e as práticas amorosas na educação, na vida e nas relações cotidianas, sobretudo, "Porque amor desse, cresce primeiro; brota é depois" (ROSA, 1986, p. 192).

Uma educação que olha para o ser humano dessa forma, continua exaltando a razão, mas na mesma proporção que exalta o Eros. Em grego, Eros significa prazer, amor, paixão. Para ensinar não basta ter domínio disciplinar do saber e habilidade para usar recursos materiais e teorias. É preciso gostar, sentir prazer, gostar das pessoas que estão diante de si. Essa é uma das marcas do educador humanizador. Gostar é a chave para o entusiasmo. E este, por sua vez, é a marca dos amantes que não param de se ver, de conversar, de se encontrarem. Não se cansam. Não se bastam. Gostar de ensinar é mais necessário do que a falta de materiais, porque quando gostamos, criamos as próprias condições de criação. Paulo Freire sabia disso e se tornou um exemplo a esse respeito.

No processo ensino-aprendizagem é assim que acontece: o ensino exige prazer de quem ensina e o prazer de todas as pessoas envolvidas. Parece impossível existir um grande educador humanizador que não sinta prazer pelo que faz. Mesmo que ele domine toda a teoria e técnicas de ensino, de conteúdos, se ele não tiver amor pelo que faz, prazer em estar com o outro, se não gostar de si mesmo, estará prestando um desserviço social e educacional imenso.

No processo de humanização do humano, os aspectos do Eros e das paixões humanas são fundamentais tanto no ensino como nas aprendizagens. Concordarmos 
com Rouanet (2009, p. 533) ao dizer que as paixões tornam a vida mais humana, que reerotizam o mundo, que resgatam o prazer e a sensualidade, pois concebemo-las como construtora de novos significados e conhecimentos sobre o ser, a vida e sobre o próprio conhecimento. É sabido que:

não existe nenhuma disciplina científica que tenha o amor como objeto. $\mathrm{O}$ amor nãoé estudado nem pela psiquiatria, nem pela psicanálise, nem pela psicologia social. O amor é uma coisa que você vai ter que procurar nos artistas, na televisão, no cinema, e, principalmente, na poesia (LEMINISKI, 2009, p. 333).

O que Leminski diz se aplica igualmente a paixão. Nenhuma disciplina acadêmica ou nenhuma ciência estuda as paixões humanas que moveram a humanidade, por exemplo.

É importante esclarecer que quando falamos em paixão atualmente, associamos a mesma imediatamente a enamoramento e amor. Mas paixão não se restringe somente a isso. Entendemos por paixão aquilo que Morin (1995, p.10) chama de demons: forças poderosas, entidades espirituais, ao mesmo tempo, inferiores e superiores a nós, a quem obedecemos sem saber. Essa força habita o estrato movediço da alma humana. São esses demons que nos possuem enquanto não compreendemos que são as nossas origens vivas. Paixão seria aquela sensação muitas vezes incompreendida que nos move, que nos faz realizar algo imensuravelmente maior do que supúnhamos poder. Como disse Morin se referindo ao amor como um demon, somos duplamente possuídos e possuímos o que nos possui (MORIN, 2008, p. 22). E fato perceptível que, por trás de cada discurso, de cada ação, de cada gesto ou voz apaixonada, está o demônio da paixão humana dando a sonoridade e poesia da fala que acontece naquele instante-já.

Temos a necessidade de um conhecimento capaz de compreender o mundo, o amor, a vida, as pessoas, até o próprio conhecimento. E isso requer prudência, temperança, comedimento, desprendimento, determinação, estratégias, método. Mas tudo indica que essa razão não se sustenta sozinha ou por si só. O questionamento feito por Morin é extremamente pertinente: "Até que ponto minha necessidade de conhecimento é ela mesma racional?" (MORIN, 2008, p.66). Sentimos também a necessidade de amor, paixão, entusiasmo e encantamento para fazermos as coisas e apostarmos nos sonhos possíveis e nas utopias realizáveis. Ao certo, razão e paixão se entrelaçam e constroem, juntas, as cores e a consistência da existência humana (FONSECA; EVANGELISTA; QUEIROZ, 2011).

Somos seres que buscamos diariamente um sentido maior do que o tamanho das ações circunstanciais. Esse sentido emerge quando a intensidade de um ato consome e expressa, ao mesmo tempo, todo o sujeito. As paixões, todas elas, tem essa força. A poesia tem essa intensidade.

Reconhecemos a poesia não apenas como um modo de expressão literária, mas comoum estado segundo do ser que advém da participação, do fervor, da admiração, da comunhão, da embriaguez, da exaltação e, obviamente, do amor, que contém em si todas as expressões desse estado segundo (MORIN, 2008, p. 9).

Precisamos pensar, contemplar, estimular, construir e valorizar a beleza das relações humanas presentes nos lugares de encontro e aqueles presentes nos gestos que tocam a humanidade dos outros.

\section{POR UMA EDUCAÇÃO DOS GESTOS POÉTICOS}


Discutir a educação na perspectiva da sensibilidade ou uma educação para o coração não é uma tarefa fácil, visto que tratar questões relacionadas à afetividade, escuta sensível e compreensão tem sido secundarizado ou mesmo negligenciado em nossa sociedade. Nesse cenário de dualidades excludentes, tomamos de empréstimo os versos de Cecília Meireles (2002):

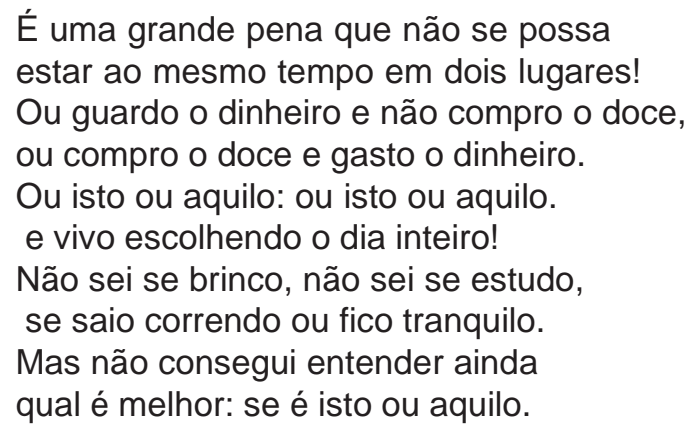

Em apreciação ao poema, pedimos licença a Cecília e defendemos outros trajetos de escolhas. Na dinâmica da vida, os caminhos são plurais, assim, as coisas podem ser isto, aquilo e/ou muito mais. "Tudo é complexo: a realidade física, a lógica, a vida, o ser humano, a sociedade" (MORIN, 2000, p. 133).

Ao longo da história, mais precisamente com o advento da razão, um novo "pensar racional" foi proporcionado, com isso, presenciamos a lógica da racionalidade firmarse como modelo único e instância confiável, capaz de mensurar e explicar a realidade dos fatos. Nessa hegemonia do pensar racional, a educação foi influenciada de forma negativa pelos princípios mercadológicos, individualismo, competividade e produtivismo, ensinando o indivíduo a atingir o alvo, o sucesso e a ascensão profissional. Modelo guiado pelo mercado e pela técnica, privilegia a razão e promove a cisão do sensível no homem. A incorporação desse paradigma nos processos educativos priva-nos de uma educação dos afetos, das sensibilidades, do saber viver com-o-outro e do saber ser, uma educação reconhecedora da condição humana da integralidade.

Não somos defensores da lógica binária: racionalidade versus sensibilidade, pois um conhecimento não é superior ao outro. Na perspectiva da formação humanística e compreensiva da condição humana, o que não se pode é descartar um conhecimento em nome de um saber dominante, pois ambos precisam ter o mesmo espaço e importância no processo formativo dos sujeitos. Como diz Santin, é preciso "demonstrar ao homem contemporâneo que a sensibilidade deve ocupar um lugar mais significativo na vida individual e em toda ordem cultural, já que dela está propositalmente afastado em nome das normas da racionalidade" (SANTIN, 1997, p. 4).

O desafio está no entrelaçamento e arejamento das diferentes dimensões de conhecimentos e saberes em defesa de um ensino preocupado com a formação integral do ser humano, pois, como nos lembra Morin:

O homem da racionalidade é também o da afetividade, do mito e do delírio (demens). O homem do trabalho é também o homem do jogo (ludens). $\mathrm{O}$ homem empírico é também o homem imaginário (imaginarius). O homem da também o da poesia, isto é, do fervor, da participação, do amor, do êxtase (MORIN, 2000, p. 58).

Nesse sentido, o ser humano é um indivíduo racional e sensível. Portanto, carece Rev. Omni. Sap., Mossoró, v.1, n.1, p. 13-25, ago./nov. 2021. 
de um processo educacional para a sensibilidade, de uma formação que propicie, além do saber técnico, um conhecimento tecido nos sentidos, no imaginário, sociabilidade, irrigado pela afetividade, poesia, emoções, esperanças, devaneios e sonhos, pois como nos diz Mia Couto (2011, p. 12), "os sonhos falam em nós o que nenhuma palavra sabe dizer".

Considerado o exposto, é possível dizer que a educação, fundamentada na sensibilidade dos gestos poéticos e na formação humana, constitui-se um solo fértil para nos ajudar a enfrentar as concepções redutoras que não enxergam o homem em sua inteireza e silencia os sentimentos, visão hegemônica nos espaços acadêmicos e impregnada na vida cotidiana. Neste mundo marcado pela razão, o ser humano e os seus sentimentos são desprezados. É preciso avançar para entender que a mente aprendiz, para ter a compreensão lógica das coisas e do mundo a nossa volta, carece de construir sentidos e significados.

Qual seria, então, a contextura dos gestos poéticos potencializados em nossas reflexões? Por onde avançar nesse itinerário que propicie a formação de um sujeito mais sensível e mais humano? Um olhar que eduque para uma poética das relações humanas?

Poética é um termo polissêmico: "Uma poética pode denotar um enfoque sobre a estética ou sobre qualquer forma de arte, tais como a poesia ou o drama" (HANSEN, 2005, p. 95). Na concepção de uma Educação Integral que defendemos, a poética dos gestos, para que o homem possa cultivar sua própria humanidade, é carregada de densidade estética e tem esse sentido alargado, manifestado não somente na poesia, mas na literatura, na música, no teatro e no cinema. O exercício educativo de humanização exige tanto de ciência como das artes no geral.

Ernesto Sabato (2008, p. 26) tem razão ao dizer que "foi necessário uma crise geral da sociedade para essas verdades simples, porém humanas, ressurgirem com todo o seu vigor. Estamos perdidos se não revertermos, com energia, com amor, essa tendência". Tudo nos diz que o mundo está carente desses gestos: mansos e obstinados, simples e profundos, firmes e leves. Gestos poéticos são quaisquer gestos que rompem com a rotina, que negam a repetição, que tocam o coração de alguém; são palavras e ações que nos levam ao outro e nos colocam em contato com nossos eus profundos, porque no íntimo de nosso eu, encontra-se o outro, a humanidade. Quando buscamos a nós mesmos é que encontramos em nós os outros, a nossa "legião estrangeira", nas palavras de Clarice Lispector. Ou como bem nos explica o poeta Octavio Paz (1996, p. 34) "Eu buscava a mim mesmo e nessa busca encontrei meu complemento contraditório: esse tu que se torna eu; as duas sílabas da palavra teu".

Um coração que canta, um olhar que acolhe, um desejo que cria, uma imaginação que sonha o novo, uma inteligência consciente, um sorriso que resiste à crueldade, uma palavra de amor, de atenção; uma presença sentida, consentida, vivida; uma poesia que de repente nos surpreende; o cuidado, a partilha; a palavra que fala quando deveria ficar em silêncio. Bastam "só uns poucos gestos mansos e obstinados. $E$ as coisas boas adormecidas acordaram, como que por 'magia'” (ALVES, 1994, p. 7).

Pequenos gestos como esses não mudam os rumos da economia, não alteram o funcionamento das tecnologias, não faz ninguém ganhar mais ou saber mais, mas, com certeza, podem fazer a diferença no processo ensino-aprendizagem, no processo de humanização do humano. Gestos poéticos como esses podem sintonizar nossa presença com a presença do outro, podem acordar o que em nós dorme. 
"Há gestos que fazem brotar sorrisos", dizia Gandhi. E há aqueles que enchem um peito de emoção, que tiram alguém da solidão. Há gestos que são mais do que gestos: são toques de despertar. Essa é a força de um gesto poético: tocar, despertar, chamar atenção, motivar, acreditar. O professor pode, pois, aprender com o poeta: ser capaz de despertar o bem que dorme no fundo do coração humano.

O professor deve e o aluno pode ser o poeta dos gestos humanos, aqueles capazes de devolver a graça de viver a quem já não a tem; gestos capazes de tocar a sensibilidade do outro; capazes de desabrochamentos, de encantamento; gestos que expressem a leveza do ser e de ser.

Gestos de gentileza e de amor que trazem em suas raízes a capacidade de despertar, as palavras que nos fazem sonhar. Um professor poeta seria aquele capaz de reencantar o ensino/aprendizagem, o prazer de estudar e acreditar nos estudos e no futuro.

Se no sentido original do termo, educador é aquele que tem a capacidade de fazer emergir, trazer à tona, fazer desabrochar o que existe no sujeito, o educador seria, por excelência, esse poeta dos gestos poéticos: um ser capaz de despertar o bem, a humanidade, a beleza que dorme no fundo do coração humano. O educador tem um grande papel na construção desse futuro que está em gestação; ele pode ser o semeador dos gestos capazes de reinventar o homem e de construir o dia que ainda não nasceu.

Se é verdade, como disse Manoel de Barros (2016, p. 21), que "palavra que eu uso me inclui nela", posso dizer que quando falamos com amor, cada palavra que se diz é uma revelação daquele que fala. As palavras têm uma força inacreditável quando estão a serviço de nossas paixões. Como dizia o poeta Tagore (2007, p. 31), as forças criadoras são forças emocionais.

Uma educação humanizadora estimula e valoriza a grandeza desses pequenos gestos humanos poéticos proporcionadores de significativas mudanças. Assim como "qualquer gentiliza é uma declaração de amor" (Couto), um simples gesto pode provocar grandes desejos, sonhos e encantos; podem também acordar um ser humano do seu sono profundo. Pensamos como Rubem Alves (1994, p. 8), é destes gestos que nascem as grandes metamorfoses: dos indivíduos, das comunidades, de povos inteiros.

Esses gestos nascem em qualquer lugar e crescem com a força e a beleza daquela flor no asfalto, da qual fala Carlos Drummond de Andrade (2002, p.118) em seu poema $A$ flor e a náusea:

(...)

Uma flor nasceu na rua!

Passem de longe, bondes, ônibus, rio de aço do tráfego.

Uma flor ainda desbotada

llude a polícia, rompe o asfalto.

Façam completo silêncio, paralisem os negócios,

Garanto que uma flor nasceu.

Sua cor não se percebe.

Suas pétalas não se abrem.

Seu nome não está nos livros.

É feia. Mas é realmente uma flor.

(...)

É feia. Mas é uma flor. Furou o asfalto, o tédio, o nojo e o ódio. Rev. Omni. Sap., Mossoró, v.1, n.1, p. 13-25, ago./nov. 2021. 
A flor que furou o asfalto, rompeu o tédio, superou o nojo e venceu o ódio, vem esclarecer, por meio de sua força de ser, que o impossível pode se tornar possível. Ela é a possibilidade que nasceu num lugar aparentemente impossível. É uma resposta a desilusão: nasceu como a esperança que engendrará uma nova mentalidade e humanidade de fé.

\section{CONSIDERAÇÕES FINAIS}

Vivemos um momento no qual a educação assume um papel fundamental para a reconstrução do novo milênio. E neste novo tempo, a educação não deve se consolidar somente como o caminho para se alcançar uma profissão, ou levar o sujeito a se inserir no mercado de trabalho em busca de realização e felicidade. A educação cumprirá um papel indispensável na missão de formar um ser humano aberto ao outro, sendo estes capazes de estenderem as mãos uns aos outros, aproximarem os corações, estreitarem laços, construírem pontes e plantarem a esperança. Se assim for, a educação não estará apenas construindo um novo homem para o mundo, mas também um novo mundo para um novo homem. Somente assim teremos uma cultura da paz.

\section{REFERÊNCIAS}

ALVES, Rubem. Gandhi: política dos gestos poéticos. São Paulo: FTD, 1994.

ANDRADE, Carlos Drummond. Poesia completa. Rio de Janeiro: Nova Aguilar, 2002.

BARROS, Manoel de. O livro das ignorãças. Rio de Janeiro: Alfaguara, 2016.

CÂNDIDO, Antônio. Direitos Humanos e literatura. In: FESTER, Antônio Carlos Ribeiro. (Org.). Direitos humanos E... Brasília: Brasiliense, 1989.

COUTO, Mia. E se Obama fosse africano? e outras interinvenções - Ensaios. São Paulo: Companhia das Letras, 2011.

DOLORS, Jacques et al. Educação um tesouro a descobrir: relatório para a UNESCO da Comissão Internacional sobre educação para o século XXI. Tradução de José Carlos Eufrázio. São Paulo: Cortez; Brasília: UNESCO; MEC, 2001.

ENRIQUEZ, Eugène. Caminho para o outro, caminho para si. Revista Sociedade e Estado, Brasília, v. 9, n. 12, jan./dez., 1994.

FONSECA, Ailton Siqueira de Sousa; EVANGELISTA, Jucieude de Lucena; QUEIROZ, Allan Phablo. A paixão tece os saberes que nos fazem falar. In: VIEIRA, José Glebson; SOUZA, Karlla Christine de Araújo; VON ZUBEN, Marcos de Camargo (Org.). Sujeito, saberes e práticas sociais. Mossoró: Edições UERN, 2011. p. 215-228.

HANSEN, João Adolfo. Reorientações no campo da leitura literária. In: ABREU, Márcia; 
SCHAPOCHNIK, Nelson (Org.). Cultura letrada no Brasil: objetos e práticas. Campinas: Mercado de Letras, 2005.

KRISHNAMURTI, J. A educação e o significado da vida. Tradução de Hugo Veloso. São Paulo: Cultrix, [s.d.].

LEMINSKI, Paulo. Poesia: a paixão da linguagem. In: NOVAES, Adauto (org.). Os sentidos da paixão. São Paulo: Companhia das Letras2009. p.322-350.

LISPECTOR, Clarice. Onde estivestes de noite (contos). Rio de Janeiro: Rocco, 2007.

MEIRELES, Cecília. Ou isto ou aquilo. 6. ed. Rio de Janeiro: Nova Fronteira, 2002.

MORIN, Edgar. Ciência com consciência. Rio de Janeiro: Bertrand, 2000.

MORIN, Edgar. Os sete saberes necessários à educação do futuro. Tradução de Catarina Eleonora F. da Silva e Jeane Sawaya. São Paulo: Cortez, 2000b.

MORIN, Edgar. O método 5: a humanidade da humanidade: a identidade humana. Tradução de Juremir Machado da Silva. Porto Alegre: Sulina, 2002.

MORIN, Edgar. Amor, poesia e sabedoria. Tradução de Edgard de Assis Carvalho. Rio de Janeiro: Bertrand Brasil, 2008.

MORIN, Edgar. Meus demonios. Traduçao de Fernando Martinho. Lisboa: Publicações Europa-América, 1995.

NUNES, César. Educação em Direitos Humanos no Brasil Atual: Fundamentos políticos e práticas pedagógicas emancipatórias possíveis. In: NUNES, César Augusto R.; GOMES, Catarina (Orgs.). Direitos Humanos, Educação e Democracia. Jundiaí: In House, 2019.

PAULO, Freire. Educação como prática da liberdade. 14. ed. Rio de Janeiro: Paz e Terra, 1983.

PAULO, Freire. Pedagogia da autonomia: saberes necessários à prática educativa. Rio de Janeiro: Paz e Terra, 1996.

PAZ, Octavio. Vislumbres da Índia: um diálogo com a condição humana. Tradução de Olga Savary. São Paulo: Mandarim, 1996.

ROSA, Guimarães. Grande Sertão: Veredas. Rio de Janeiro: Nova Fronteira, 1986.

ROUANET, Sergio Paulo. Razao e paixao. In: NOVAES, Adauto (Org.). Os sentidos da paixão. São Paulo: Companhia das Letras, 2009. p.500-536.

ROUSSEAU, Jean-Jacques. Projeto para a Educação do Senhor de Sainte-Marie. Rev. Omni. Sap., Mossoró, v.1, n.1, p. 13-25, ago./nov. 2021. 
Tradução de Dorothée de Bruchard. Porto Alegre: Paraula, 1994.

ROUSSEAU, Jean-Jacques. Emílio ou Da Educação. São Paulo: Martins Fontes, 2004.

SANTIN, S. Educação e Sensibilidade. 1997. Disponível

em: http://silvinosantin.wordpress.com/about/. Acesso em: 10 maio 2021.

SAVIANI, Dermeval. Escola e Democracia. 25.ed. São Paulo: Cortez, 1991.

TAGORE, Rabindranath. Meditações. Tradução de Ivo Storniolo. São Paulo: Idéias \& Letras, 2007. 